\title{
PROCEDENCIA DEL HABEAS DATA, EL DERECHO A LA INTIMIDAD Y LA FIGURA DE LA PRESCRIPCION. LAS PERSONAS ERRONEAMENTE REPORTADAS EN LAS CENTRALES DE RIESGO
}

\author{
Autores; Alexander Caicedo Villamizar ${ }^{1}$ \& Esther Cecilia Miranda Estrada;² \\ Correspondencia: esthermiranda_90@hotmail.com
}

\begin{abstract}
RESUMEN
El objetivo de este trabajo de investigación, es un análisis de los precedentes jurídicos expresados por la Corte Constitucional sobre la procedencia del habeas data, el derecho a la intimidad y la figura de la prescripción cuando las personas son erróneamente reportadas en las centrales de riesgo. Para lograr tal propósito se toma como referencia la Constitución Política de Colombia de 1991 en el Artículo 15, que establece que todas las personas tienen derecho a su intimidad personal y familiar y a su buen nombre y el Estado se encuentra en la obligación respetarlos y hacerlos respetar. De igual modo, tienen derecho a conocer, actualizar y rectificar la información que se hayan recogido sobre ellos en Banco de Datos y en archivos de entidades públicas y privadas.
\end{abstract}

La figura de la prescripción se encuentra consagrada en el Artículo 2512 del Código Civil colombiano de 1887.

Por esta razón el Habeas Data y la prescripción, se convierten en una herramienta para el ciudadano colombiano con la cual hacen valer la protección al buen nombre, a la intimidad personal y familiar y protección de su información como derecho fundamental.

\section{Palabras clave}

Habeas Data, Prescripción, Deudores, Obligación

\section{ABSTRACT}

The objective of this research is an analysis of the legal precedents expressed by the Constitutional Court on the merits of the habeas data, the right to privacy and the statute of limitations when people are mistakenly reported in credit bureaus. To achieve this purpose is referenced to the Constitution of Colombia of 1991 in Article 15, which states that everyone has the right to personal and family privacy and your good name and the State is obliged respect and ensure respect. Similarly, the right to know, update and rectify information gathered about them on Database and records of public and private entities.

The statute of limitations is enshrined in Article 2512 of the Colombian Civil Code of 1887.

\footnotetext{
${ }^{1}$ Abogado. Docente Investigador

${ }^{2}$ MIRANDA Estrada Esther Cecilia, Estudiante de Derecho de la Corporación Universitaria Rafael Núñez. Investigación Realizada con los siguientes estudiantes investigadores, ARIZA Vásquez Guillermo Arturo, ORELLANO Bustillo Jairo Junior.
} 
For this reason the Habeas Data and prescription, become a tool for Colombian citizen with which assert protection good name, personal and family privacy and protection of your information as a fundamental right.

\section{Keywords}

Habeas Data, Prescription, Debtors, Obligation

\section{INTRODUCCIÓN}

El Habeas Data es el derecho que tienen todas las personas en conocer, actualizar, rectificar información que se haya recogido sobre ella en Bancos de Datos y archivos de entidades públicas y privadas. Así lo define la Constitución Política de 1991 en el Artículo 15 (Colombia. Asamblea Nacional Constituyente) y posteriormente desarrollado por la Ley 1266 del 2008. (Colombia. Congreso de la República, 2008)

Se puede decir que el Habeas Data, por lo tanto supone una garantía sobre la adecuada manipulación de la información personal que se encuentra bajo conocimiento de terceros. Esto permite impedir abusos y corregir los errores involuntarios en la administración y publicación de dichos datos.

La Corte Constitucional se ha pronunciado sobre este tema en reiteradas Sentencias, por ejemplo, en la SU-082/1995 y la SU-089/1995, expresando lo siguiente "por cuanto el termino no puede ser el mismo, para aquel deudor que cancela en relación a aquel deudor que ha cancelado, esta corporación, ante la evidencia del vacío legal ya mencionado, el juez debe llenarlo acudiendo al razonamiento analógico" (Colombia. Corte Constitucional, 1995); que enseña que donde existe la misma razón debe aplicarse la misma disposición, en este caso la regla general de la prescripción de la acción ordinaria civil y debe señalar que el termino de almacenamiento de datos de individuos que no hayan cancelado sus obligaciones financieras serán de 10 años. 
Vol. 6, No. 1 Diciembre de 2014 pp. 80 - 88

El Código Civil en el Artículo 2512 define que la prescripción es un modo de adquirir las cosas ajenas, o extinguir las acciones o derechos ajenos por haberse poseído las cosas y ejercido dichos derechos acciones durante cierto lapso de tiempo y concurrido los demás requisitos legales. Se prescribe una acción o derecho cuando se extingue por la prescripción. (2008)

Así mismo es importante recordar, que con la expedición de la Ley 1266 del 2008 o la Ley del Habeas Data, toda la jurisprudencia de la Honorable Corte Constitucional, mantiene la vigencia en la interpretación y defensa de los derechos al buen nombre y al habeas data y que mantiene vigente la jurisprudencia emitida sobre estos temas.

La Constitución Política de Colombia de 1991 consagra el derecho a la intimidad y el buen nombre en el Artículo 15. Esta garantía hace parte del catálogo de derechos fundamentales que cualquier ciudadano puede invocar para solicitar la protección bajo el ordenamiento constitucional.

A través de este trabajo se analizará la Línea Jurisprudencial para determinar la protección y mecanismos con que los ciudadanos colombianos cuentan, al igual que se hará un análisis y se determinará cuáles son los derechos que se vulneran a los colombianos que son reportados erróneamente en las centrales de riesgos.

\section{MATERIALES Y MÉTODOS}

Se considera, que los materiales utilizados para el presente trabajo de Línea Jurisprudencial, son sin lugar a dudas las Sentencias dictadas por la Corte Constitucional, tales como la Sentencia T- 883 de 2013, la Sentencia T- 414 de 1992 y la SU-082 de 1995, haciendo énfasis de manera reiterada al derecho del Habeas Data el derecho a la intimidad y la figura de la prescripción cuando las personas son erróneamente reportadas en las centrales de riesgo. 
Con respecto a lo antes mencionado, se debe manifestar que la investigación ha sido desarrollada desde la perspectiva del método deductivo; siendo éste un método científico que considera que la conclusión está implícita en las premisas, las cuales son la recapitulación de todos los argumentos expresados por la Corte al momento de fallar.

Por lo tanto, las conclusiones del trabajo siguen necesariamente a las premisas: si el razonamiento deductivo es válido y las premisas son verdaderas, la conclusión sólo puede ser verdadera.

\section{RESULTADOS Y DISCUSIÓN}

Al tomar como referencia la Constitución Política de Colombia de 1991 en el Artículo 15, que establece que todas las personas tienen derecho a su intimidad personal y familiar y a su buen nombre y el Estado de respetarlos y hacerlo respetar, al igual que tienen derecho a conocer, actualizar y rectificar las informaciones que se hayan recogido sobre ellos en Banco de Datos y en archivos de entidades públicas y privadas, se está validando lo que ya está constitucionalmente establecido como derecho.

Las cifras de colombianos reportados en centrales de riesgos erróneamente es alta, muchas de estas deuda han prescrito, y las centrales de riesgo no eliminan el reporte negativo, obviando lo que la Constitución y la Ley consagran. Muchos de los ciudadanos reportados permiten este tipo de abuso, por desconocimiento del derecho de Habeas Data. También ignoran que pueden invocarla esta figura ya que su deuda tiene que ser eliminada gracias a la figura de la prescripción. 
El término de almacenamiento de datos de individuo que no halla cancelado sus obligaciones financieras serán de 10 años. Así lo señaló la Corte Constitucional en Sentencias SU-082/95 y Su-089/92. La figura de la prescripción se encuentra consagrada en el Artículo 2512 del Código Civil colombiano de 1887.

Es por esta razón que el Habeas Data y la prescripción, se convierten en una herramienta para el ciudadano colombiano para hacer valer la protección al buen nombre, a la intimidad personal y familiar y protección de su información, derechos fundamentales consagrados en la Constitución Política de Colombia de 1991 en su Artículo 15. Se hace entonces necesario que lo ciudadano colombiano conozca sus derechos y reconozca los mecanismos para hacerlos valer, provistos por la Constitución Política de Colombia de 1991, el Código Civil colombiano de 1887 en el Artículo 2512 y la Ley 1266 de 2008.

Con respecto a lo manifestado antes surge el siguiente interrogante: ¿cuáles son los pronunciamientos de la Corte Constitucional sobre el derecho de Habeas Data, el derecho a la intimidad y la figura de la prescripción cuando las personas son reportadas erróneamente en las Centrales de Riesgo?. La respuesta a esta pregunta aparece consignada en las diferentes Sentencia que sobre el tema han tratado en Colombia, las cuales son presentadas a continuación en la siguiente Tabla.

Tabla 1. Jurisprudencia y Punto de Ruptura en las Sentencias que tratan sobre el Habeas Data

\begin{tabular}{|l|c|}
\hline \multicolumn{1}{|c|}{ SI } & NO \\
\hline Sentencia T- 414 1992 & \\
\hline Sentencia SU- 082 1995 & \\
\hline Sentencia T- 527 2000 & \\
\hline Sentencia T- 284 2008 & Sentencia T- 883 2013 \\
\hline
\end{tabular}


A través del estudio realizado, que se percibe en la información presentada en la Tabla anterior, se puede destacar que hay una ruptura de criterios sobre este tema en la Sentencia arquimédico (T-883/2013), que se distancia de lo expresado en las Sentencias fundadoras e hito (T- 414/1992 y SU- 082/1995). En las anteriores legislaciones se tenía como prioridad la prevalencia del derecho sustancial y de la eficacia, que según el Artículo Tercero del Decreto 2591 de 1991, deben regir el trámite de la acción de tutela.

Sostenía que esto da pié para formular algunas consideraciones adicionales acerca del alcance que tiene la expresión "esta acción sólo procederá cuando el afectado no disponga de otro medio de defensa judicial" (Constitución Política de 1991).

Si se repara que en el inciso primero de dicho Artículo la Acción de Tutela aparece consagrada como un procedimiento para la protección inmediata de los derechos constitucionales fundamentales, como quiera que éstos resulten vulnerados o amenazados por la acción o la omisión de cualquier autoridad pública; que en la función pública de administrar justicia debe prevalecer el derecho sustancial y se observará la debida diligencia (Constitución Nacional, Artículo 228); y que entre los fines esenciales del Estado está el de garantizar la efectividad de los derechos consagrados en la Constitución (Artículo Segundo), está fuera de toda duda que la Acción de Tutela, por la expresa voluntad del Constituyente de 1991, es el recurso efectivo que consagran los tratados y convenios internacionales para proteger eficazmente los derechos fundamentales. Por tanto, así se ha venido a colmar en el ordenamiento nacional un vacío que justamente venía preocupando a personas y entidades comprometidas en la protección de tales derechos.

Siendo esto así, es claro entonces que el otro medio de defensa judicial a que alude el Artículo 86 antes citado, debe poseer necesariamente, cuando 
Vol. 6, No. 1 Diciembre de 2014 pp. 80 - 88

menos, la misma eficacia en materia de protección inmediata de derechos constitucionales fundamentales que, por su naturaleza, tiene la Acción de Tutela. De no ser así, se estaría haciendo simplemente una burda y mecánica exégesis de la norma, en abierta contradicción con los principios vigentes en materia de efectividad de los derechos y con desconocimiento absoluto del querer expreso del Constituyente.

En la Sentencia T -883/2013 hubo un cambio total en el criterio de los Magistrados de la Corte Constitucional. Aquí se consideró que debía haber un cambio en la Jurisprudencia en este punto concreto por cuanto, de aceptarse la tesis según la cual puede acudirse directamente a la Tutela para pedir que retiren el nombre de la persona de un Banco de Datos alegando prescripción de las obligaciones que dieron lugar a su registro, el Juez de Tutela estaría desplazando al ordinario competente en la definición de un derecho ajeno al asunto mismo sobre el cual recae el amparo del Artículo 86 constitucional, que consiste únicamente en la protección del derecho fundamental consagrado en el Artículo 15: que se actualicen y rectifiquen las informaciones recogidas sobre el peticionario en Bancos de Datos o en archivos de entidades públicas o privadas.

La prescripción de la acción cambiaria o de una obligación no puede alegarse ante el Juez de Tutela ni ser reconocida por éste, sino ante el Juez competente.

\section{CONCLUSIONES}

El desconocimiento de la norma que en esta investigación se trató representa igualmente un grave irrespeto a la dignidad y tranquilidad de los colombianos. Amerita la intervención de las autoridades competentes, particularmente por cuanto con la vigencia de la Carta de 1991 no hay duda alguna que el Estado debe estar al servicio de la persona y no la persona al servicio ciego del Estado. 
En efecto, según el Artículo 306 del Código de Procedimiento Civil, el juez puede reconocer oficiosamente en la sentencia los hechos que constituyen una excepción, salvo las de prescripción, compensación y nulidad relativa, las que deberán alegarse en la contestación de la demanda.

Así pues, el competente para resolver si se ha producido o no la prescripción de la acción cambiaria respecto de una determinada obligación es aquel juez al que corresponda decidir sobre el proceso que instaure el acreedor con miras a su cobro. Si ni siquiera el juez competente puede reconocer una prescripción si ante él no se alega y se la somete al pertinente estudio jurídico, menos aún puede el Juez de Tutela - ajeno al proceso en que se debate lo relativo al derecho del acreedor y a la obligación del deudor-, partir del supuesto de que ha operado la prescripción de la acción cambiaria o de la obligación misma y de que, por tanto, no cabe ya la vía ejecutiva, para, con base en ello, concluir que el Banco de Datos debe eliminar toda referencia al nombre del deudor.

Por todo lo anterior después de analizadas y estudiadas las sentencias base de este trabajo se pudo determinar que, la Tutela no es procedimiento para declarar prescripciones, ya que esta materia corresponde a una jurisdicción distinta de la constitucional. Y si el juez de tutela carece de jurisdicción, tampoco tiene competencia.

\section{BIBLIOGRAFÍA}

Colombia. Corte Constitucional. (1995). Sentencia SU- 082 del 1 de marzo de 1995, expediente T- 40.966

Colombia. Corte Constitucional. (1995). Sentencia T 414 del 16 de junio de 1992, Expediente T- 534. 
Colombia. Corte Constitucional. Sentencia T 883 del 3 de diciembre de 2013, Expediente T- 3.980 .656

Bernal, C. (2010). Metodología de la investigación. 2ª Ed. Bogotá: Pearson

Colombia. Congreso de la República. (2013). Código Civil. Bogotá: Legis

Colombia. Congreso de la República. (2013). Código de Comercio. Bogotá: Legis

Colombia. Asamblea Nacional Constituyente. (2013). Constitución Política de Colombia, 1991. Bogotá: Legis

Colombia. Congreso de la República. (2013). Procedimiento Civil. Bogotá: Legis 